\title{
O PROCESSO DE SOLUÇÃO DE PROBLEMAS EM CRIANÇAS COM DEFICIÊNCIA MENTAL LEVE: A RELAÇÃO ENTRE O REAL E O VIRTUAL ${ }^{1}$
}

\author{
THE PROBLEM SOLVING PROCESS IN CHILDREN WITH MILD MENTAL DEFICIENCE: \\ THE RELATION BETWEEN REAL AND VIRTUAL THE PROBLEM SOLVING PROCESS IN \\ CHILDREN WITH MILD MENTAL DEFICIENCE: THE RELATION BETWEEN REAL AND
}

VIRTUAL

Sandra Lúcia Silva ARAÚJO²

\begin{abstract}
RESUMO: este artigo trata de uma pesquisa realizada com vinte e duas crianças com deficiência mental leve tendo como objetivo estudar o processo de solução de problemas dessas crianças em duas situações diferentes - uma situação denominada real e uma situação virtual. Esses sujeitos foram divididos em dois grupos experimentais: Grupo Experimental I e Grupo Experimental II. Como resultado, verificamos a supremacia da situação virtual (para ambos os grupos) e a supremacia do Grupo Experimental II (Virtual - Real - Virtual). Consideramos que essa supremacia pode ser explicada pelo fato de que a situação virtual possui uma característica de monitoramento, que permite à criança com deficiência mental leve ter um feedback imediato quanto às estratégias escolhidas; uma forma de aprendizagem mais gradual, onde lhes é possível aprender a organizar e integrar informações, e, também, uma situação onde elas sejam menos expostas ao medo do fracasso.
\end{abstract}

PALAVRAS-CHAVE: solução de problema; deficiência mental leve; virtual - real.

ABSTRACT: this article is about a research made with twenty two children with mild mental retardation in order to study the process of problem solution of these children in two different situations - one called real and the other called virtual. These individuals were divided into two testing groups: Testing Group I and Testing Group II. As a result, we have verified a predominance of the virtual situation (for both groups) and a predominance of the Testing Group II (Virtual - Real - Virtual). We understand that the predominance of the virtual situation and the Testing Group II can be explained by the fact that the virtual situation has a helping feature, which provides the children with mild mental retardation an immediate feedback concerning the selected strategies; it's a more gradual way of learning, which allows them to learn how to organize and connect information, and it's also a situation in which they can be less exposed to the fear of failing.

KEYWORDS: problem solving; mild mental retardation; virtual - real.

\section{INTRODUÇÃo}

A solução de problemas é considerada por muitos autores, de diferentes enfoques, como o tipo de aprendizagem de nível mais complexo e difícil, pois requer mais que uma aplicação imediata do conhecimento acumulado em aprendizagens anteriores. Para solucionar problemas é necessário que a pessoa elabore um plano de ação, que teste hipóteses, que selecione as estratégias adequadas das inadequadas, dentre outras coisas (STERNBERG, 1992 e 2000). Lester

\footnotetext{
${ }^{1}$ Este artigo é uma versão reduzida da pesquisa de doutorado (ARAÚJO, 2005) realizada no Programa de PósGraduação em Educação Escolar - FCLAr/Unesp.

${ }^{2}$ Doutora em Educação Escolar - saneduc@hotmail.com 
(1983) define esse tipo de aprendizagem como uma situação que um indivíduo ou um grupo quer ou precisa resolver e para a qual não dispõe de um caminho rápido e direto que o leve à solução.

A habilidade para solucionar problemas é comumente difícil para as pessoas sem deficiência em relação aos problemas mais complexos e abstratos. Em se tratando de pessoas com deficiência mental, pode-se dizer que é nesse ponto que elas freqüentemente esbarram e fracassam. As pesquisas sobre o processo de solução de problemas mostram que pessoas com deficiência mental leve são consideradas capazes de realizar tarefas cognitivas simples, mas inábeis para resolverem sozinhas problemas mais complexos, por vários motivos. Alguns autores apontam haver uma dificuldade acentuada para essas pessoas, sejam elas crianças, jovens ou adultos, na execução de tarefas que envolvam maior elaboração mental; os autores afirmam que ao tentar realizar essas tarefas, as pessoas com deficiência mental exibem pouco uso de mecanismo de controle, de planejamento ou conhecimento de sua própria habilidade, dificuldade de planejar e de aplicar o uso de estratégias de solução, como também acentuada passividade ou impulsividade (ALLARDICE; GINSBYRG, 1983; CHERKES-JULKOWSKI, 1985).

Uma outra concepção muito comum com relação a essas pessoas é que elas raramente produzem e generalizam espontaneamente estratégias de solução de problemas para outras situações ou problemas (CAMPIONE; BROWN, 1978; MINSKY; SPITZ; BESSELLIEU, 1985). De acordo com outros autores, essa dificuldade de generalização atua como um verdadeiro entrave para a solução de problemas e para a efetuação de aprendizagens mais complexas; nesse sentido, os programas de intervenção devem ser organizados de modo a favorecer as condições ideais para a aprendizagem e generalização de estratégias (KEPHART, 1990; MARCHESI; MARTÍN,1995).

Algumas pesquisas têm mostrado que as pessoas com deficiência podem aprender estratégias de solução de problemas se tiverem intervenção educativa adequada, apesar das dificuldades apresentadas por elas na aprendizagem de solução de problemas. Por exemplo, Erez e Pelet (2001) em uma pesquisa realizada com 15 adolescentes com deficiência mental leve envolvendo tarefas-problema, mostraram que todos esses sujeitos exibiram algum grau de metacognição relacionado a duas categorias: I) conhecimento sobre seu próprio conhecimento; II) organização e reflexão sobre seu comportamento. As principais conclusões extraídas dessa pesquisa apontam para a importância do comportamento metacognitivo como elemento-chave para a efetiva solução de problemas e apontam que este componente deve ser promovido pela educação escolar desde a mais tenra idade. Outro estudo, realizado por Tanaka et al. (2001), mostrou que indivíduos com deficiência mental fazem mais uso de pistas externas como guias para a ação do que seu próprio recurso cognitivo. Esse estudo mostrou que, dentre uma população de indivíduos com deficiência mental, a ocorrência desses comportamentos foi mais comum nos adultos. A explicação dos autores 
para a exibição desses comportamentos em adultos é a de que eles supostamente tiveram mais experiências de fracasso do que as crianças, o que quer dizer que o comportamento desfavorável à solução de problema deve-se mais à experiência de vida do que à própria deficiência. Quanto ao nível dessa experiência, os autores salientam a importância de se trabalhar conteúdos e estratégias de solução de problemas com a criança, principalmente de um modo que garanta seu sucesso nessas tarefas e que esse sucesso possa ajudá-la a usar menos esse estilo em tarefas complexas.

Outros autores Zigler; Hodapp (1986) também defendem que experiências bem sucedidas devem ocorrer o mais cedo possível, pois, do contrário, as pessoas com deficiência mental podem desenvolver nenhuma ou pouca iniciativa, desamparo quanto à aprendizagem, auto-imagem negativa e uma falta de desejo de tentar. Para garantir esse sucesso é necessário que algumas condições sejam respeitadas e seguidas. Quanto a isso, Ferretti (1989) faz uma observação muito interessante - o autor afirma que crianças com deficiência mental podem apresentar estratégias de solução se elas compreendem as exigências/ requerimentos do problema e se constroem uma representação adequada do mesmo. É interessante destacar as considerações de Agran et al. (2002) de que a solução de problemas é um ponto crítico para o sucesso na escola e na comunidade e que, embora isso seja tão importante, é freqüentemente uma área muito negligenciada no currículo para indivíduos com deficiência mental. Portanto, destaca-se a intervenção educativa como essencial para que essas pessoas possam ser auxiliadas quanto ao uso de estratégias para a solução de problemas.

Nesse sentido, a revisão dessa literatura nos leva a indagar se existiriam outras formas, além das convencionais, que pudessem propiciar esse apoio como, por exemplo, o uso adequado e sistemático da informática, ou seja, se situações virtuais planejadas poderiam também ajudar pessoas com deficiência mental leve a desenvolver estratégias de solução de problemas, e se estas situações virtuais ofereceriam algum tipo de vantagem com relação às não virtuais, ou em outras palavras, às situações reais ou convencionais.

Assim sendo, o objetivo desta pesquisa consiste em estudar como crianças com deficiência mental leve solucionam problemas em duas situações diferentes: uma situação que denominamos real (ou convencional) e uma situação virtual (que envolve o uso de software).

\section{Metodologia}

Sujeitos - Analisamos 22 crianças, sendo 16 delas do sexo masculino e 06 do sexo feminino, de uma escola especial, na faixa etária dos 10 aos 12 anos e 5 meses e, de acordo com diagnóstico psicológico feito pela Instituição, possuem deficiência mental leve.

Equipamentos - Tanto nas sessões virtuais como nas reais utilizamos uma filmadora JVC, fitas de vídeo e tripé, para a filmagem das sessões. 
Material - Especificamente para a situação real utilizamos uma caixa de madeira de aproximadamente $26 \times 21 \times 13 \mathrm{~cm}$, com tampa frontal de plástico transparente que podia ser facilmente levantada e um conjunto de três pequenos bastões de comprimentos diferentes $(7,5 \mathrm{~cm}, 15 \mathrm{~cm}, 23 \mathrm{~cm})$ e igual grossura, que podiam ser encaixados em furos nas laterais de pequenos blocos $(4 \times 2 \times 2 \mathrm{~cm})$, compondo varas curtas, médias ou longas (ver a seguir a Figura B - desenho esquemático). Já na situação virtual, utilizamos um computador e um software elaborado especialmente para esta pesquisa. Para fazer os registros, contamos com um aparelho de TV, vídeo cassete e um computador. Para melhor identificar estas categorias e para encontrar a freqüência de cada uma delas, utilizamos o software “Etholog 2.2", desenvolvido por Ottoni (2000).

Local da Pesquisa - As sessões foram realizadas na APAE de Araraquara/ SP, nos meses de abril e maio de 2004, no período da manhã e da tarde.

Procedimento - As sessões foram aplicadas por um único experimentador e cada criança passou por duas situações diferentes: uma em que o problema a ser resolvido - problema do tipo isca ${ }^{3}$ - era apresentado numa situação "real" e outra em que o problema era apresentado na situação virtual.

1. As sessões experimentais reais compunham-se de um período de 8 minutos de treinamento e após isso, a apresentação de duas situações-problema: as Tarefas I e II. As tarefas consistiam em retirar o objeto que a própria criança escolhia dentre várias opções e que era colocado dentro da caixa à sua frente, sobre a mesa, mas fora do seu alcance. A criança devia permanecer sentada à mesa e de frente para a caixa, e tinha como restrição não se levantar do lugar, o que lhe era dito em forma de instrução. A única solução possivel consistia em construir varas com os bastões e blocos, usá-las para alcançar a caixa e tentar puxar o objeto para si. Para a Tarefa I a criança contava com um conjunto de 6 bastões ( 2 grandes, 2 médios e 2 pequenos) e um único bloco; o brinde só poderia ser obtido encaixando-se os dois bastões maiores no bloco, dada a distância em que a caixa era colocada (ver Figura A). Para a Tarefa II, a criança dispunha de 1 conjunto de 9 bastões ( 3 grandes, 3 médios e 3 pequenos) e 2 blocos; neste caso, o brinde só poderia ser obtido encaixando-se os três bastões maiores nos dois blocos, uma vez que a caixa se encontrava a uma distância ainda maior da criança (ver figura B).

\footnotetext{
${ }^{3}$ Significa situação-problema em que um objeto, ou brinde, colocado fora do alcance do sujeito, deve ser obtido ou recuperado por meio de instrumentos. O problema do tipo isca foi utilizado anteriormente por Rodrigues (1994 e 1995) e na pesquisa de Silva (2000).
} 


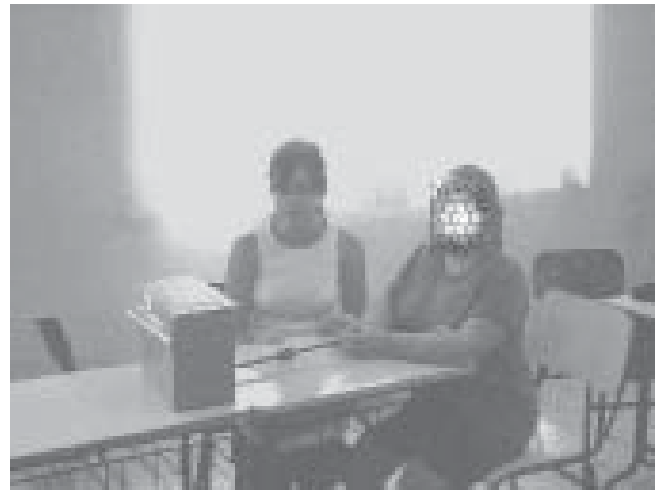

Figura A. Solução da Tarefa I.

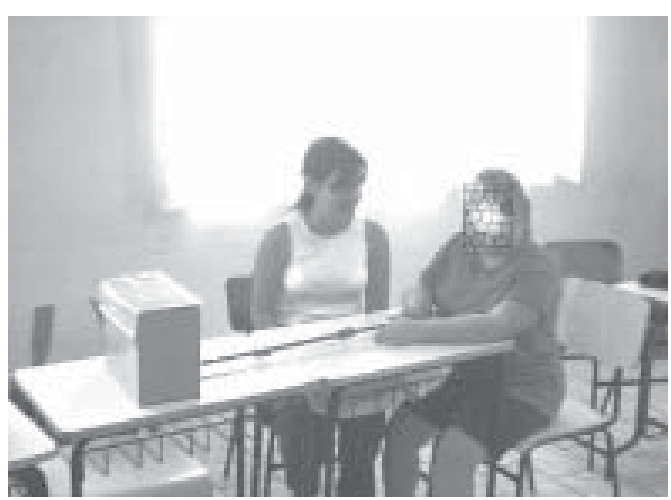

Figura B. Solução da Tarefa II.

2. O mesmo tipo de problema era oferecido nas sessões experimentais virtuais. Nestas, as mesmas crianças realizavam, em um software, um problema de natureza semelhante ao dos bastões e blocos contando, no entanto, com os recursos da informática presentes nas animações, nos sons e nas cores. O software que usamos foi desenvolvido no programa Flash.

O jogo tipo isca era apresentado em três fases:

Fase 1 - a solução somente era possível por meio do uso de uma vara grande, a maior entre três varas $(a, b, c)$ de tamanhos diferentes, que no caso é $a$ vara $c$. Este problema foi oferecido três vezes, ou seja, em três etapas, mudando apenas a posição das varas.

Fase 2 - a caixa era colocada mais acima e a solução somente era possível por meio do uso de uma vara grande, a maior entre quatro varas (a, b, c, d) de tamanhos diferentes, sendo a vara $d$ a maior de todas. Aqui também o problema compreendia três etapas.

Fase 3 - a solução somente era possível por meio do encaixe de duas varas grandes, formando uma vara ainda maior. Nesta última fase, a criança tinha que descobrir a solução, pois esta era bem diferente das vivenciadas nas fases anteriores em que era necessário utilizar apenas uma vara.

seguir:

O jogo tipo isca oferecido na situação virtual pode ser visualizado a 


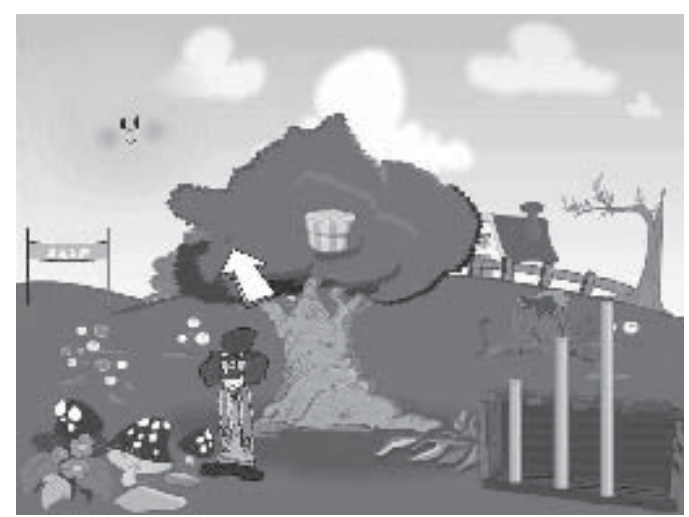

Figura C. Uma das etapas da Fase 1 do jogo Tipo Isca.

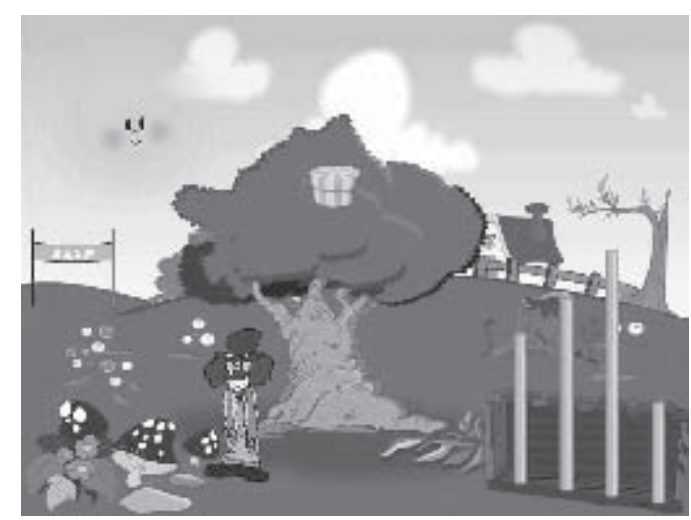

Figura D. Uma das etapas da Fase 2 do jogo Tipo Isca.

Tanto para a situação real como para a virtual, se a criança não exibisse sinais de tentar resolver o problema ou não apresentasse qualquer iniciativa dentro do $1^{\circ}$ minuto, era dada, então, uma primeira dica; outras dicas eram dadas se a criança não prosseguisse nas tentativas de solução ou se mostrasse muita dificuldade.

Tivemos dois tipos de sessões experimentais - as sessões reais e as virtuais. Todas as crianças passaram por ambas as sessões experimentais, sendo que um grupo passou primeiramente pela situação real e depois a virtual e, o outro grupo fez o caminho inverso. A finalidade dessa seqüência estava em verificar se esses sujeitos conseguiriam transferir as estratégias aprendidas como corretas de uma situação para outra e se também conseguiriam reter a aprendizagem após um intervalo de 24 horas, como pode ser visto no quadro a seguir.

\begin{tabular}{|c|c|c|c|c|}
\hline Grupo & \multicolumn{2}{|c|}{ Teste } & $\begin{array}{c}\text { Pós-teste } \\
(24 \text { horas })\end{array}$ & $\mathrm{N}^{\circ}$ de sujeitos \\
\hline I & Real & Virtual & Real & 11 (8 meninos e 3 meninas $)$ \\
\hline II & Virtual & Real & Virtual & 11 (8 meninos e 3 meninas $)$ \\
\hline Total & \multicolumn{3}{|r|}{22 (16 meninos e 6 meninas $)$} \\
\hline
\end{tabular}

Quadro 1 - Desenho esquemático do experimento.

A designação de cada criança para seu respectivo grupo foi feita aleatoriamente, por meio de um sistema de sorteio. 


\section{Procedimento de coleta e tratamento de Dados}

A coleta de dados foi feita por meio de leitura dos filmes de todas as sessões. Registramos o tempo gasto em cada tarefa, o número de dicas dadas, a quantidade de acertos como também os comportamentos exibidos por nossos sujeitos. Cada criança foi observada individualmente. Para fazer o registro do desempenho, transcrevemos tudo o que cada criança fazia e dizia. Com base nessas transcrições, os desempenhos puderam ser reunidos e organizados em seis grupos de Categorias Gerais de Ações tanto para a situação real como para a virtual: Ações que implicam nas soluções dos problemas (A), que abrangem o que podemos caracterizar como desempenhos apropriados para a solução das tarefas oferecidas nas duas situações; ações que somente envolvem o próprio corpo (B) representando aquelas subcategorias que não implicam em uso dos materiais ou do mouse ali disponíveis; ações que envolvem uso dos materiais/mouse e que podem levar à solução (C), que constituem-se em estratégias acertadas, ou seja, que se aproximam da solução e que abrangem o uso correto e ordenado dos materiais disponíveis e do mouse para se chegar mais perto da obtenção do brinde; ações que acompanham o planejamento/ raciocínio (D), que podem envolver ou não o uso dos materiais e do mouse, mas são caracterizadas por demonstrar um conjunto de fatores que parecem acompanhar o "planejamento" da criança para a solução, como, por exemplo, coçar a cabeça quando o problema está difícil; ações isoladas (E), que, embora envolvam uso dos materiais e do mouse, parecem não revelar qualquer relação do uso desses objetos com a elaboração de um plano para solucionar o problema, e ações que parecem revelar distância do problema (F), que são significativas por mostrarem que a criança pode não se envolver de forma alguma com a situação e, desse modo, não chegar à solução. Temos assim, dois extremos: a categoria $\mathrm{A}$, que se refere à solução e a categoria $\mathrm{F}$, em que a criança faz uso de estratégias que não levam à solução.

Os dados foram reunidos considerando-se a média de tempo gasto em cada sessão (convertido em segundos), a média de dicas dadas e o percentual de acertos do grupo em cada uma das tarefas. Por meio dos relatórios gerados pelo software "Etholog", reunimos dados a respeito da freqüência média de cada uma das categorias comportamentais. Encontradas as médias, aplicamos testes estatísticos a fim de saber se os resultados foram significantes ou não (teste t-Student e ANOVA). Fizemos a análise de cada grupo considerando-se o desempenho dos sujeitos: nas tarefas de cada situação (real e virtual), de uma situação para a outra, do teste para o pós-teste e de um grupo para o outro.

\section{Resultados}

No Grupo I, as tarefas que mais exigiram de nossos sujeitos foram a TI (que é a primeira tarefa de todas na situação real), a E1 (que é a primeira etapa de todas na situação virtual, onde os sujeitos tinham que descobrir que deveriam usar o mouse para pegar o presente) e a F3 (a fase 3, que constituiu-se na tarefa mais difícil na situação virtual, em que os sujeitos deveriam emendar duas varas). 
Houve mais tempo gasto, mais necessidade de dicas e uso de diversas categorias nessas tarefas do que nas restantes. Quanto ao percentual de acertos, notamos (na Figura E) uma melhora da TI para a tarefa seguinte, uma melhora da TI para a E1 (da situação real para a virtual), totais percentuais de acertos em toda a situação virtual.

No pós-teste, houve expressiva melhora da Tarefa I para tempo, dicas, acertos e categorias; quanto à Tarefa II, é curioso notar que não houve melhora significante como era de se esperar, pelo contrário, o tempo médio, a quantidade de dicas, o percentual de acertos e as categorias comportamentais foram praticamente iguais aos encontrados no teste. No entanto, devemos destacar que esses resultados se referem a apenas um sujeito da amostra, que não se saiu bem em todas as tarefas da situação real, tanto no teste como no pós-teste; as demais crianças melhoraram seu desempenho de um dia para o outro, o que mostra que o Grupo I se saiu bem, havendo melhora dentro da situação real, da virtual, de uma situação para a outra, do teste para o pós-teste. De todas as situações deste grupo, notamos que a situação que ofereceu maior vantagem foi a virtual, visto que nesta houve um número elevado de solução de problemas e uma menor ocorrência das categorias que envolvem ações isoladas e ações que se distanciam da solução dos problemas, como pode ser visto na figura $G$.

No Grupo II , como no grupo anterior, houve maior quantidade de tempo, dicas e categorias nas duas tarefas mais difíceis da situação virtual - E1 (primeira etapa) e F3 (fase mais difícil); na situação real, esses fatores ocorreram mais na TI (que é a primeira). Quanto ao percentual de acertos, na figura F podemos notar que houve melhora da E1 para as etapas seguintes na situação virtual; houve melhora de uma situação para a outra e dentro da situação real houve alto percentual de acertos. Devemos destacar aqui, que o número menor de acertos na situação real refere-se a apenas uma criança que não solucionou essas duas tarefas, o que indica que as demais se saíram bem.

Houve expressiva melhora do teste para o pós-teste, em todas as tarefas da situação virtual quanto à diminuição do tempo gasto, à queda total das dicas, elevado percentual de acertos, e à queda das categorias B, D, E, F na Fase 3 do teste para o pós-teste (como pode ser visto na Figura H), mostrando que esses sujeitos realmente se saíram muito melhor no dia seguinte. 


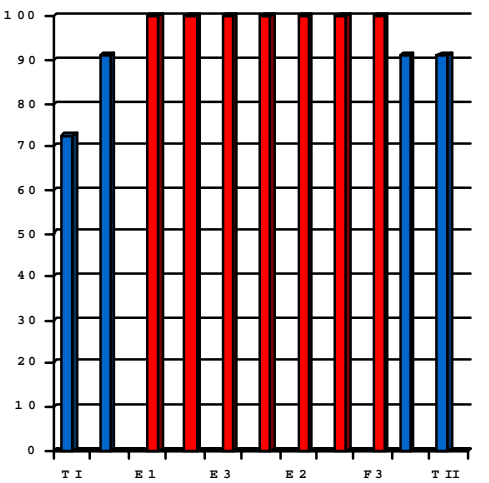

Figura E. Percentual de acertos ocorridos no Grupo I.

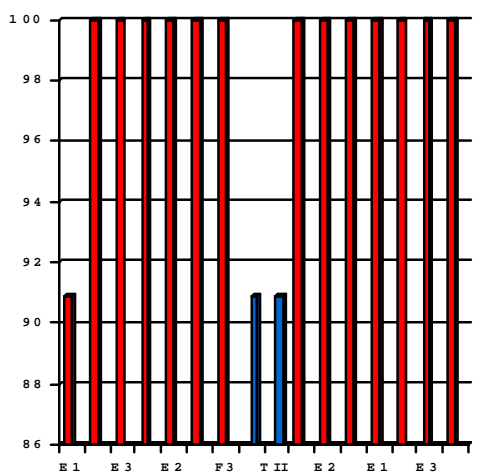

Figura F. Percentual de acertos ocorridos no Grupo I.
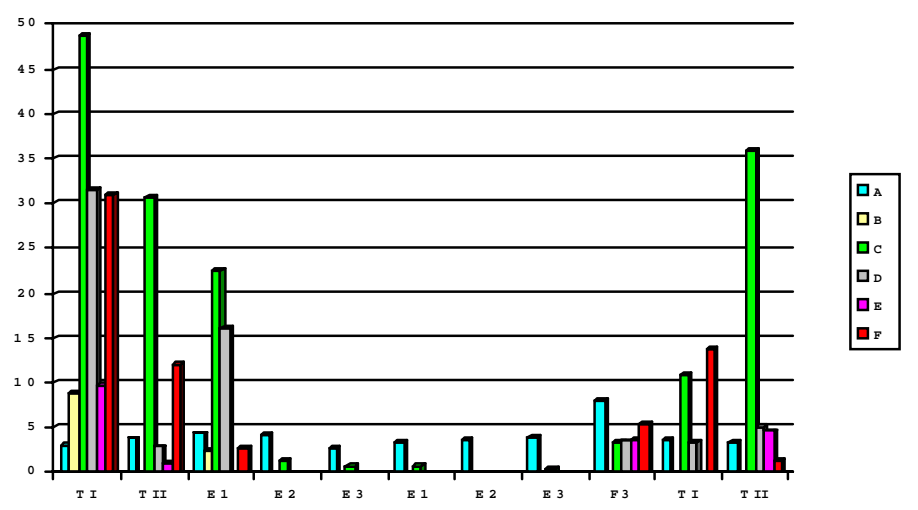

Figura G. Freqüência média das categorias comportamentais (A,B,C,D, E e F) nas sessões experimentais do Grupo I.

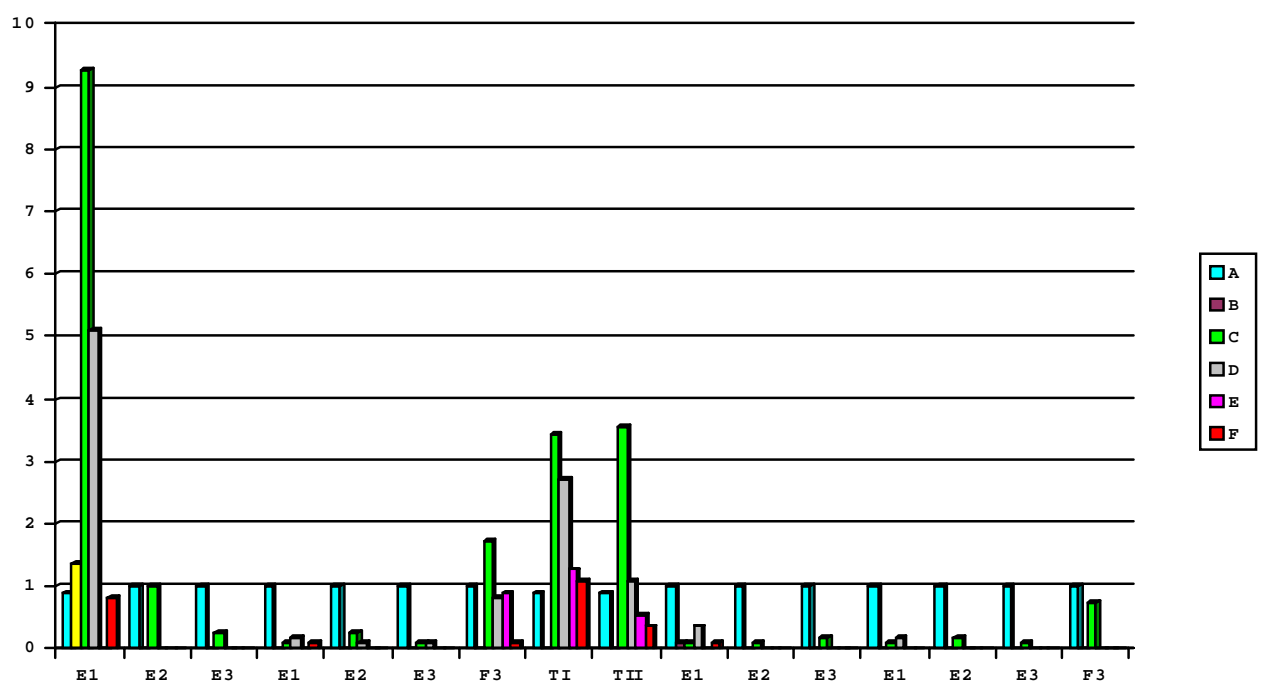

Figura H. Freqüência média das categorias comportamentais (A,B,C,D, E e F) nas sessões experimentais do Grupo II. 
De um modo geral, os resultados mostraram que houve melhora no desempenho dos sujeitos: de uma tarefa para outra, de uma situação para outra, do teste para o pós-teste, em ambos os grupos. Podemos, pois, apontar ter havido transferência e retenção de aprendizagem tanto nas sessões do Grupo I como nas do Grupo II. Entretanto, analisando minuciosamente os resultados, notamos que houve diferença para melhor em uma situação mais do que em outra e em um grupo mais do que em outro.

Os dados dessa pesquisa nos levam a afirmar que a situação virtual foi, de fato, a que mais garantiu sucesso a essas crianças, tanto às do Grupo I (que já haviam tido experiência anterior na situação real) como as do Grupo II (que não possuíam nenhuma experiência prévia com esse jogo), principalmente no que diz respeito ao percentual de acertos, e que o grupo que provavelmente se saiu melhor foi o Grupo II, dados os resultados referentes às tarefas desse grupo do teste para o pós-teste.

\section{ConClusão}

Nossa interpretação para esses resultados fundamenta-se no fato de que a situação virtual parece possuir uma característica de monitoramento, permitindo que a criança tenha um feedback imediato quanto às estratégias que são tomadas durante o processo de solução de problemas. Tal monitoramento parece orientar a criança, de um modo mais eficaz, se ela está seguindo ou não o caminho mais correto, sem, contudo, interferir de modo indesejável em seu raciocínio.

Além disso, a estrutura da situação virtual permitiu que as tarefas fossem apresentadas paulatinamente, passando de um grau de dificuldade mais simples para o mais complexo. Essa característica paulatina pode ter colaborado para que houvesse maior sucesso por parte dessas crianças na situação virtual, uma vez que exigiria um tipo de raciocínio mais seqüencial, o que talvez seja mais indicado para as pessoas com deficiência mental leve.

A importância dessa característica pode estar no fato de que o tipo de raciocínio seqüencial parece auxiliar essas crianças a processarem mais eficientemente as informações, considerando-se que, ao contrário das demais crianças, essa habilidade se efetue de um modo mais difícil para elas. Nesse sentido, a situação virtual pode ter sido mais vantajosa justamente pelo fato de favorecer um tipo de aprendizagem que considere uma seqüência progressiva de passos.

Talvez isso explique porque o Grupo II se saiu melhor. É que neste grupo, os sujeitos provavelmente foram aprendendo a organizar informações e separar as estratégias adequadas das inadequadas, etapa por etapa, indo do mais fácil para o mais difícil. Uma outra explicação para considerarmos o Grupo II como superior e que, inclusive, complementa a explicação anterior, é a de que a situação virtual oferece um ambiente de aprendizagem mais propício para esses sujeitos, no sentido de lhes oferecer uma segurança emocional maior para testar suas idéias 
e até mesmo para errar na escolha das estratégias. Ou seja, na situação virtual, como foi aqui descrita, elas se sentem menos expostas ao medo do fracasso e/ou da crítica o que lhes dá mais liberdade para testar.

Quando falamos em situação virtual não queremos com isso subestimar a importância da situação real e nem sugerir que uma situação deve ser substituída por outra, mas, ao contrário, queremos alertar, baseado em nossos dados, que é na situação real que esses sujeitos têm mais dificuldade e que mais precisam de apoio. Nesse sentido, quando comparamos o real com o virtual, queremos encontrar os melhores meios para que a situação real possa ser mais efetiva e melhor aproveitada, garantindo mais sucesso às crianças com deficiência mental leve.

Também não queremos dizer que o computador deve excluir a intervenção do professor e que deve haver uma interação restrita da criança com o jogo. Ao contrário, a combinação da intervenção da experimentadora com o monitoramento do jogo virtual podem ter criado uma situação que possibilitou a essas crianças adquirirem, com ajuda, a habilidade de solucionarem o problema do tipo isca, tanto na situação virtual como na real, ou seja, talvez possamos dizer que o conhecimento mediado pelos recursos do jogo virtual, juntamente com a intervenção da experimentadora podem ter criado uma situação favorável para o desenvolvimento de zonas de desenvolvimento proximal (VIGOTSKI, 1996) mais do que as condições permitidas pela situação real.

Essa situação favorável parece também ter possibilitado a essas crianças adquirirem uma maior independência e autonomia, dados os resultados obtidos no pós-teste. Além disso, a comparação entre as categorias do teste para o pósteste no Grupo II mostrou que houve diminuição dos comportamentos que não levaram à solução.

Para finalizar nossa conclusão, gostaríamos de apontar algumas sugestões que surgiram em decorrência desse trabalho. Primeiramente devemos destacar a importância de se efetuar pesquisas que contemplem o ensino de um determinado conteúdo escolar em uma situação comum de sala de aula e este mesmo conteúdo trabalhado em uma situação virtual. Acreditamos que outras pesquisas, dentro dessa temática, fornecerão dados que completem os nossos quanto à situação mais vantajosa e também quanto à ordem mais eficaz de se trabalhar cada situação para essa população em especial.

Uma outra colocação que temos a fazer é a da necessidade de se produzir mais pesquisas considerando duas populações: a de crianças com deficiência mental leve e a de crianças sem deficiência mental. Acreditamos, também, que a produção de pesquisas que estudem detalhadamente o processo de solução de problemas desses dois tipos de indivíduos trará bastante informação não somente quanto ao processamento de informação dos indivíduos com deficiência mental como também oferecerá significativas contribuições para a educação escolar. 
Devemos ressaltar, ainda, a necessidade de se produzir pesquisas sobre o uso da informática em uma população de pessoas com deficiência mental moderada e severa. Será que essas pessoas conseguiriam realizar tarefas em uma situação mais do que em outra? Ou ainda, será que elas conseguiriam aprender um determinado conteúdo nas duas situações ou haveria apenas uma delas em que fosse possível efetuar a aprendizagem? Se elas, de fato, somente conseguirem realizar tarefas em apenas uma situação, como a outra situação poderia ser melhor aproveitada usando os recursos desta?

Ao lado dessas sugestões, gostaríamos de finalizar esse trabalho com a seguinte questão: será que a pessoa que soluciona problemas mais complexos torna-se mais inteligente? Por inteligência entendemos a capacidade de selecionar, comparar e combinar, com mais eficiência e rapidez, informações relevantes e irrelevantes; de generalizar informações em outros domínios e contextos e de pensar sobre o próprio processo de pensamento.

Se, de fato, solucionar problemas ajuda as pessoas a tornarem-se mais capazes de usar seu raciocínio, então pensamos que talvez um caminho para as pessoas com deficiência mental, considerando-se seu desenvolvimento cognitivo, seja investir em pesquisa e no ensino de solução de problemas para essas pessoas. Nesse sentido, julgamos extremamente importante a produção de trabalhos de pesquisa básica que resultem, em última análise, em subsídios a serem seriamente considerados nos trabalhos de formação de professores e de outros profissionais que lidam com essa população.

Esperamos, então, que outras pesquisas possam surgir trazendo mais contribuições em torno dessa temática. De nossa parte, esperamos ter mais insights quanto aos dados dessa pesquisa, a fim de podermos discuti-los melhor e oferecer contribuições.

\section{REFERÊNCIAS}

AGRAN, et al. Increasing the problem-solving skills of students with developmental disabilities participating in general education. Remedial and Special Education, Austin, v. 23, n.5, p. 279-88, 2002.

ALLARDICE, B. S; GINSBYRG, H. P. Children's psychological difficulties in mathematics. In: GINSBURG, H. P. The development of mathematic thinking. New York: Academic Press, 1983.

ARAÚJO, S.L.S. O processo de solução de problemas em crianças com deficiência mental leve - a relação entre o real e o virtual. 2005. 283 f. Tese (Doutorado em Educação Escolar) - Faculdade de Ciências e Letras, UNESP, Araraquara.

CAMPIONE, J. C. ; BROWN, A. L. Toward a theory of intelligence: contributions from research with retarded children. Intelligence, v. 2, p.279-304, 1978. 
CHERKES - JULKOWSKI, M. C. Metacognitive consideration in mathematics instruction for the learning disabled. In: CAWLEY, J. F. (org). Cognitive strategies and mathematics for the learning disabled. Aspen: CO. Aspen Systems Corporation, 1985.

EREZ, G. ; PELET, I. Cognition and metacognition: evidence of higher thinking in problem-solving of adolescents with mental retardation. Education and Training in Mental Retardation and Developmental Disabilities, Reston, v.36, n. 1, p. 83-93, 2001.

FERRETTI, R. P. Problem solving and strategy production in mentally retarded persons. Research in Developmental Disabilities, Baton Rouge, v.10, p.19-31, 1989.

HICKSON, L.; KHEMKA, I.. Decision making and mental retardation. International Review of Research in Mental Retardation, New York, v. 22, p.227-265, 1999.

KEPHART, N. O Aluno de Aprendizagem Lenta. Trad. Ieda Luci Sehm Gerhardt. Porto Alegre: Artmed, 1990.

LESTER, F.K. Trends and issues in mathematical problem solving research. In: LESH, R.; LANDAU, M. (orgs). Acquisition of mathematics concepts and processes. New York: Academic Press, 1983.

MARCHESI, A.; MARTÍN, E. Desenvolvimento metacognitivo e problemas de aprendizagem. In: COLL, C., PALACIOS, J. ; MARCHESI, A.(org.). Desenvolvimento psicológico e educação - necessidades educativas especiais e aprendizagem escolar. Tradução de Marcos A. G. Domingues. Porto Alegre: Artmed, 1995. v. 3

MINSKY, S. K.; SPITZ, H. H; BESSELLIEU, C. L. Maintenance and transfer of training by mentally retarded young adults on the tower of hanoi problem. American Journal of Mental Deficiency, Washington, v. 90, n. 2, p.190-197, 1985.

OTTONI, E.B. Etholog 2.2 - a tool for the transcription and timing of behavior observation sessions. Behavior Research Methods, Instruments \& Computers, Austin, v.32, n.3, p.446-449, 2000.

RODRIGUES, M. A. Brincadeira orientada: efeito do lúdico ou da relação professoraluno? Projeto Integrado CNPQ n. 52.1151/95 e 52.3873/94.

SILVA, S. L. Indicativos de insight na solução de problemas do tipo lure-retrieval por préescolares, 2000, 197 p. Dissertação (Mestrado em Educação Escolar) - Faculdade de Ciências e Letras, UNESP, Araraquara, 2000.

STERNBERG, R. J. As capacidades intelectuais humanas: uma abordagem em processamento de informações. Tradução de Dayse Batista. Porto Alegre: Artes Médicas, 1992.

. Psicologia cognitiva. Tradução de Maria Regina Borges Osório. Porto Alegre: Artes Médicas, $1^{a}$ edição, 2000. 
TANAKA, M. et al. Development of an outerdirected style of problem solving in individuals with and without mental retardation. Applied Developmental Psychology, Washington, n.22, p.191-198, 2001.

VIGOTSKI, L. S. A Formação social da mente: o desenvolvimento dos processos psicológicos superiores. Tradução de José Cipolla Neto et al. São Paulo: Martins Fontes, 1996.

ZIGLER, E.; HODAPP, R. M. Understanding mental retardation. Cambridge: Cambridge University Press, 1986.

Recebido em 07/07/2005

Reformulado em 16/12/2005

Aprovado em 22/12/2005 